\title{
Exposure to Tetrachloroethylene-Contaminated Drinking Water and the Risk of Pregnancy Loss
}

\author{
Ann Aschengrau • Janice M. Weinberg • Lisa G. Gallagher • Michael R. Winter • \\ Veronica M. Vieira · Thomas F. Webster · David M. Ozonoff
}

Received: 7 November 2008 / Revised: 5 January 2009 / Accepted: 6 January 2009 / Published online: 30 January 2009

(C) The Author(s) 2009. This article is published with open access at Springerlink.com

\begin{abstract}
There is little information on the impact of solvent-contaminated drinking water on pregnancy outcomes. This retrospective cohort study examined whether maternal exposure to tetrachloroethylene (PCE)-contaminated drinking water in the Cape Cod region of Massachusetts influenced the risk of clinically recognized pregnancy loss. The study identified exposed $(n=959)$ and unexposed $(1,087)$ women who completed a questionnaire on their residential and pregnancy histories, and confounding variables. Exposure was estimated using water distribution system modeling software. No meaningful associations were seen between PCE exposure level and the risk of clinically recognized pregnancy loss at the exposure levels experienced by the study population. Because PCE remains a common water contaminant, it is important to continue monitoring its impact on women and their pregnancies.
\end{abstract}

Keywords Tetrachloroethylene $\cdot$ Perchloroethylene . Drinking water contamination · Pregnancy loss . Spontaneous abortion $\cdot$ Stillbirth

\footnotetext{
A. Aschengrau ( $\varangle)$

Department of Epidemiology, Boston University School of Public Health, Boston, MA, USA

e-mail: aaschen@bu.edu
}

J.M. Weinberg

Department of Biostatistics, Boston University School of Public

Health, Boston, MA, USA

L.G. Gallagher · V.M. Vieira · T.F. Webster · D.M. Ozonoff Department of Environmental Health, Boston University School of Public Health, Boston, MA, USA

M.R. Winter

Data Coordinating Center, Boston University School of Public

Health, Boston, MA, USA

\section{Introduction}

From May 1968 through March 1980, many public water departments in the New England area installed vinyllined asbestos-cement (VL/AC) water distribution pipes to prevent taste and odor problems. The vinyl lining, which was comprised of a slurry of vinyl toluene resin (Piccotex $\left.{ }^{\circledR}\right)$ dissolved in the solvent tetrachloroethylene (perchloroethylene, PCE), was painted onto the inner surface of the pipe during manufacturing. VL/AC pipes were shipped to the water departments for installation after drying for 48 hours (Demond 1982). Because PCE is volatile, it was assumed that most of it would evaporate by the time the pipe was in use. However, large quantities of PCE remained in the lining and subsequently leached into the public drinking water supplies.

Approximately 660 miles of VL/AC pipes were installed in Massachusetts. A large proportion was installed in the Cape Cod region either to replace existing pipes or to extend the water distribution system as the population grew. When the pollution was discovered in 1980, affected areas had levels ranging from 1.5 to $80 \mu \mathrm{g} / \mathrm{L}$ in pipes along main streets with medium and high water flow and from 1,600 to $7,750 \mu \mathrm{g} / \mathrm{L}$ in pipes along dead end streets with low water flow (Demond 1982). Most areas with elevated PCE concentrations were subsequently flushed with large volumes of water or remedied by continuously bleeding the lines until levels fell below $40 \mu \mathrm{g} / \mathrm{L}$, the Suggested Action Guide at the time. The maximum contaminant level is currently $5 \mu \mathrm{g} / \mathrm{L}$. During this period, levels of other measured drinking water contaminants were low (Swartz et al. 2003).

While health concerns regarding PCE are based mainly on its carcinogenicity (IARC 1995; U.S. Department of Health and Human Services 2005), there are also concerns regarding an adverse effect on reproduction. Many animal 
experiments suggest a harmful impact of prenatal exposure to PCE, and the closely related solvent trichloroethylene (TCE), on offspring viability in rats, chicks, and rabbits (Healy et al. 1982; Bross and DiFranceisco 1983; Nelson et al. 1980; Narotsky and Kavlock 1995; Schwetz et al. 1975; Elovaara et al. 1979; Beliles et al. 1980).

Epidemiological studies of pregnancy loss among women with occupational exposure to dry-cleaning solvents have also observed positive associations (e.g., Bosco et al. 1987; Kyyronen et al. 1989; Kolstad et al. 1990; Olsen et al. 1990; Lindbohm et al. 1990; Windham et al. 1991; Doyle et al. 1997). Only a few studies with mixed results have examined women exposed to solvent-contaminated drinking water (Lagakos et al. 1986; Bove et al. 1995; Massachusetts Department of Public Health 1996).

We undertook a population-based retrospective cohort study to examine the influence of maternal exposure to PCEcontaminated drinking water on variety of pregnancy and developmental outcomes, including low birth weight, prematurity and learning disabilities (Aschengrau et al. 2008; Janulewicz et al. 2008). The current report focuses on the risk of pregnancy loss following PCE exposure, using the reproductive histories reported by women in the parent cohort study.

\section{Materials and Methods}

\section{Selection of Study Population}

This study was approved by the Institutional Review Boards of the Massachusetts Department of Public Health and Boston University Medical Center, and by the 24A/B/11B Review Committee at the Massachusetts Department of Public Health.

Women were eligible for the parent cohort study if they gave birth to a child (termed "index child") from 1969 through 1983 and were living in one of eight Cape Cod towns with some VL/AC water distribution pipes at the time of the child's birth. Eligible women were identified by crossmatching the maternal address on the birth certificate against water distribution system data gathered from water department records. The latter was stored in a Geographic Information System (GIS) that included the location, installation year, and diameter of all VL/AC pipes in the region.

Two groups of women were selected for the parent study: (1) women who were exposed to PCE-contaminated drinking water when the index child was born, and (2) women who were unexposed when the index child was born. A total of 1,492 women were initially designated as "exposed" because they were living at a residence at the time of the index child's birth that was either adjacent to a VL/AC pipe or was adjacent to a pipe connected to a VL/AC pipe and
Table 1 Selection and enrollment according to woman's PCE exposure status, Cape Cod, Massachusetts

\begin{tabular}{|c|c|c|c|}
\hline & \multicolumn{2}{|c|}{ Initial exposure status ${ }^{\mathrm{a}}$} & \multirow[t]{2}{*}{ Total } \\
\hline & Exposed & Unexposed & \\
\hline Selected & 1,492 & 1,704 & 3,196 \\
\hline \multicolumn{4}{|c|}{ Excluded During Enrollment } \\
\hline Never located & 132 & 136 & 268 \\
\hline No response & 245 & 336 & 581 \\
\hline Ineligible or Deceased & 7 & 8 & 15 \\
\hline Refusal & 149 & 137 & 286 \\
\hline Returned Questionnaire & 959 & 1,087 & 2,046 \\
\hline$\%$ of selected & $64.3 \%$ & $63.8 \%$ & $64.0 \%$ \\
\hline$\%$ of located & $70.5 \%$ & $69.3 \%$ & $69.9 \%$ \\
\hline
\end{tabular}

${ }^{\text {aT }}$ The exposure status of the women's pregnancy losses and live births was later assessed. See text for details

the only possible water flow to their residence was through the VL/AC pipe. This initial designation was based on visually inspecting maps of the pipe distribution network in the immediate vicinity of the maternal address on the birth certificate.

A comparison group of women initially designated as "unexposed" was randomly selected from the remaining resident women who gave birth during this period. "Unexposed" women were frequency matched to "exposed" women on the month and year of birth of the index child. A total of 1,704 women were selected for the "unexposed" comparison group. The initial exposure status of a woman was considered tentative until questionnaire data on private well use were reviewed and extensive exposure assessments, as described below, were conducted.

Follow-up and Enrollment of Study Subjects

During 2002-2003, mothers were traced to find up-to-date addresses and telephone numbers. Letters were sent to all traced mothers (and fathers, if the mother was deceased) requesting that they complete a self-administered questionnaire. Two follow-up letters were sent to non-respondents, and individuals who did not respond to these letters were phoned. As described in Table 1, 8.4\% of the selected population could not be located, $18.2 \%$ were located but never responded to any of our contact attempts, and $8.9 \%$ refused to participate. A small percentage of subjects $(0.5 \%)$ were deceased or were ineligible because the birth certificate address was a temporary residence. Overall, $64.0 \%$ of the selected population and $69.9 \%$ of the successfully traced population returned the self-administered questionnaire. These percentages were similar for both "exposed" and "unexposed" subjects.

When we compared the demographic characteristics of participants and non-participants, we found that the race 
of non-participants $(96.2 \%$ white) was nearly identical to that of the participants (96.2\% white). However, nonparticipating women were younger (mean age 26.0 vs. 27.5 years), and less educated (11.3\% did not graduate from high school vs. $3.6 \%$ ) than participating women. These differences were present for both exposed and unexposed nonparticipants.

The self-administered questionnaire gathered information on maternal demographic characteristics; a complete history of all pregnancy outcomes, including prior losses; data on prenatal care, smoking, alcohol intake for each pregnancy; medical conditions such as diabetes and hypertension; occupational exposure to solvents; and use of solventbased spot removers, and professional and self-service drycleaning. In addition, information was collected on the family's residences from 1969 to 1990, including the calendar years of residence, street address, and drinking water source for all Cape Cod residences. While we attempted to collect information on the mothers' water consumption and bathing habits at these residences, this information could not be recalled well enough to permit a meaningful analysis. Lastly, to evaluate the presence of recall bias, we gathered information on women's knowledge of the PCE contamination episode, including whether or not they believed that their own drinking water may have been contaminated.

Following receipt of a completed questionnaire, we requested permission to review the prenatal and delivery records of index birth children. About 250 women agreed to release these records and records for 60 women were obtained. The remainder could not be located by the delivery hospital or obstetrician. The reproductive histories and related information in these medical records were compared to those reported by women in the self-administered questionnaires. We also compared reproductive history data reported on the birth certificates with those on the questionnaires. The latter analyses were conducted among all index births in the study population.

\section{Geocoding of Residential Addresses}

All reported residences on Cape Cod were incorporated into a GIS by geocoding each address to a latitude and longitude using ArcGIS 8.1. We assigned each address to a parcel of land, whenever possible. All geocoding was conducted without knowledge of the exposure status or pregnancy history. Among the 5,324 reported addresses, 97.3\% were successfully geocoded. The remainder could not be geocoded because of insufficient information. Our geocoding match rate was greater than or equal to that observed in recent epidemiological studies (e.g., McElroy et al. 2003; Gilboa et al. 2006).
PCE Exposure Assessment

Women received initial exposure designations based on a visual inspection of maps of the pipe distribution network in the immediate vicinity of the address listed on the index child's birth certificate. To determine the exposure status for each reported pregnancy, we used a leaching and transport model to estimate the mass of PCE that was delivered to each residence before and during the pregnancy. The model, which was developed by Webler and Brown for our prior epidemiological studies (Webler and Brown 1993; Aschengrau et al. 2003), estimates the amount of PCE entering the drinking water using the initial PCE loading in the pipe liner, the pipe's age, and the leaching rate of PCE from the liner into the drinking water. The pipe's initial stock of PCE is based on the diameter and length of the pipe and information from the pipe manufacturer on the application of the liner. The leaching rate of PCE from the liner was determined from experiments conducted by Demond (Demond 1982).

The algorithm also requires an estimate of water flow and direction, which are functions of the geometry of the distribution system and number of water users. In the current study, we estimated water flow and direction by incorporating the Webler and Brown algorithm into EPANET water distribution system modeling software. Developed by the U.S. Environmental Protection Agency, EPANET software has been used for exposure assessment of drinking water contaminants in several epidemiological studies (Rossman 1994; Aral et al. 1996; Gallagher et al. 1998; Maslia et al. 2000; Reif et al. 2003).

Using GIS maps of subject residences and a town's entire water distribution system, we created a diagram in EPANET depicting the water source locations; pipe length, diameter and composition; and nodes, the points along the pipe where water consumption occurs. Information on the locations, installation dates, and diameters of all VL/AC pipes was obtained from local water companies and the Massachusetts Department of Environmental Protection (DEP). The available information described the water system conditions around 1980, and so we chose this year as representative of the water flow during the entire study period.

We assigned each residence to the closest node on the distribution system. We assumed that land parcels represented water users and that all users on the network drew the same amount of water. These were reasonable assumptions because the study area was mainly comprised of residences. We also assumed that water sources did not change over the study period. The distribution systems in place by the $1960 \mathrm{~s}$ and early 1970s remained largely unchanged until population growth required the addition of a few water sources in the late 1980s.

The EPANET software incorporated these data to simulate the instantaneous flow of water through thousands of 
pipe segments in each town's network and to estimate the mass of PCE in grams delivered to each node and all subjects' residences associated with the node. Annual exposure assessments were conducted from 1968, the earliest installation of AC/VL pipes, through 1990. The latter cutoff was selected because of changes in population density and the water distribution systems during recent years.

We used the reproductive histories from the self-administered questionnaires to identify all clinically recognized pregnancy outcomes, including miscarriages, stillbirths, induced abortions, ectopic pregnancies, and live births. Eligible pregnancies for the current analyses were clinically recognized pregnancy losses (including miscarriages and stillbirths) and live births occurring up to December, 1990. As is typically done in retrospective studies of pregnancy outcomes (e.g., Whelan et al. 2007), induced abortions ( $n=$ $327)$ and ectopic pregnancies $(n=40)$ were excluded from the analysis. The 2,046 women who returned a study questionnaire contributed 5,567 eligible pregnancies: 659 pregnancy losses and 4,908 live births. Thus, $11.8 \%$ of eligible pregnancies resulted in a reported loss and $24.2 \%$ of women reported a prior loss at some point in their history. One hundred and fifty-six women contributed only one pregnancy while 674 contributed two pregnancies, and 1,061 contributed three or more. The number of losses per woman ranged from 0 to 6 , and the number of live births ranged from 0 to 11. A woman could contribute both exposed and unexposed pregnancies.

We calculated three measures of a woman's PCE exposure: cumulative PCE exposure up to the month and year of the last menstrual period (LMP) of the pregnancy, peak exposure up to the LMP year of the pregnancy, and average monthly PCE exposure during the LMP year. The former two measures served as estimates of pre-pregnancy exposure while the latter estimated exposure around the time of conception. The first trimester was completed during the same year as the LMP for $85 \%$ of study pregnancies, and the Pearson correlation coefficient between annual exposure levels during the LMP and first trimester years was 0.96 $(p<0.0001)$.

Cumulative exposure was estimated by summing the annual mass of PCE that entered each exposed residence from the move-in year or VL/AC pipe installation year through the month and year of the LMP. We were able to calculate only annual PCE exposures because only move-in and pipe installation years were known. Simple percentages were used to estimate the PCE exposure for a portion of a year. For example, if an exposed woman's LMP occurred in June of a particular year, we multiplied her annual PCE exposure during that year by $6 / 12$ th or 0.50 . Peak pre-pregnancy exposure was estimated from the highest annual mass of PCE that entered the residence up to the LMP year. Average monthly PCE exposure during the LMP year was estimated by dividing the annual exposure during the LMP year by twelve. The month and year of the LMP was estimated from questionnaire or birth certificate data. Pregnancies with inestimable LMPs were excluded from the analysis.

We estimated PCE exposure levels only for live births and losses associated with completely geocoded residential histories (94.2\% of reported pregnancies). Three hundred and forty-four pregnancies were associated with inadequate residential histories, and so were excluded from the analysis. All pregnancies among women who reported using a private well for their drinking water supply at a Cape Cod address (20\%) or who lived in a Cape Cod town without any VL/AC pipes were assumed to have no PCE exposure during that period. We considered these assumptions reasonable because, to the best of our knowledge, these water supplies were not contaminated with PCE in this geographic area and time period.

\section{Statistical Analysis}

The data analysis compared the occurrence of pregnancy losses among exposed and unexposed pregnancies. When cumulative exposure was examined, women who had any exposure up to the LMP were compared to those who were unexposed before the LMP, and when peak annual exposure before pregnancy was examined, any exposure before the LMP year was compared to no-exposure before the LMP year. Similarly, when exposure during the LMP year was examined, women with any exposure during the LMP year were compared to those with no-exposure during the LMP year. We used a locally weighted regression smoother (LOESS) to examine the shape of the relationship between each exposure measure and the outcome (Hastie and Tibshirani 1990). These analyses did not identify any natural cut points, so we arbitrarily divided each exposure measure into quartiles. In addition, we dichotomized the average monthly exposure during the LMP year at the level corresponding to an average drinking water concentration of $40 \mu \mathrm{g} / \mathrm{L}$, the Suggested Action Guide when the pollution was discovered in 1980 .

Generalized estimating equation (GEE) analyses were conducted to account for non-independent outcomes arising from multiple pregnancies for the same woman (Liang and Zeger 1986; Zeger and Liang 1986). The logit link was used for the outcome, assuming equal correlation between birth outcomes from the same mother. Corresponding odds ratios measured the strength of the associations and 95\% confidence intervals assessed their statistical stability.

Maternal age was included in all multivariate analyses. Additional covariates considered were either known risk factors for pregnancy loss, associated with PCE exposure, or non-drinking water sources of solvent exposure. These variables included year of pregnancy, paternal age and occupation, maternal race, educational level, number of prior live 
births, history of a prior induced abortion, history of prior losses (before any PCE exposure among exposed pregnancies and before a randomly assigned index year for unexposed pregnancies); behavioral characteristics during pregnancy including cigarette smoking, alcohol and caffeinated beverage consumption, and marijuana use; medical conditions including diabetes, thyroid disease, cervical incompetence, placental conditions, and a history of gynecologic infections; use of an intrauterine device or spermicides at conception; residence in Falmouth, the only study town with a chlorinated surface water supply (as a proxy for trihalomethane exposure during the LMP year); maternal occupational exposure to solvents, use of solvent-based spot removers and professional and self-service dry-cleaning; and the proximity of any residences to dry-cleaning establishments.

Covariates were included in the final multivariate models if they altered the maternal age-adjusted odds ratios by at least $5 \%$. Four variables met this criterion: year of pregnancy, paternal age, maternal history of gynecologic infections, and number of prior live births.

Stratified analyses were also conducted to determine if there was effect measure modification by maternal age, a history of prior losses; year of pregnancy, medical or obstetrical conditions; cigarette smoking, and alcohol consumption during the first trimester, and residence in Falmouth. Analyses were also conducted according to the trimester of the loss (first vs. second and third) in order to assess whether PCE was associated with losses arising from chromosomal abnormalities, which mainly occur during the first trimester. Lastly, analyses compared the women's selfassessed exposures from the questionnaires with the independent EPANET assessment to determine if recall bias was likely.

\section{Results}

A total of 1,891 women with 5,567 clinically recognized pregnancies were available for the final analysis. The frequency of pregnancy loss among eligible pregnancies was $11.8 \%$ and the frequency of one or more pregnancy losses among eligible women was $24.2 \%$. Following the EPANET exposure assessment, there was 283 pregnancy losses and 2,112 live births with some exposure before the LMP and 376 pregnancy losses and 2,796 live births with no-exposure before the LMP. In addition, there were 213 pregnancy losses and 1,743 live births with some exposure during the LMP year and 446 pregnancy losses and 3,165 live births with no-exposure during the LMP year.

While we were able to validate only a small number of pregnancy outcomes using original prenatal and obstetric records, we found excellent agreement between the questionnaires and medical records. For example, $92 \%$ of clinically recognized miscarriages, and $100 \%$ of the live births noted in medical record were reported in the survey. There was also excellent agreement between the medical record and survey on gestational duration, birth weight, and prenatal cigarette smoking and multivitamin use. Furthermore, when we compared the questionnaire and birth certificate data from all index births $(n=2490)$, we found good to excellent agreement on month and year of birth, mother's and father's age at the birth, birth weight, number of prior live births and number of prior pregnancy terminations (including spontaneous and induced abortions).

Many characteristics of exposed and unexposed subjects were similar (Table 2). Mothers in both groups were predominantly white, and comparable proportions had prior induced abortions, peri-conceptional contraceptive use, medical conditions and pregnancy complications, and exposure to non-drinking water sources of solvents. However, because of the timing and location of the VL/AC pipe installations, exposed losses and live births were more likely to occur in later calendar years and among residents of Falmouth, the only town with a treated surface water supply and 50 miles of VL/AC pipe. In addition, the average maternal and paternal age, maternal educational level, socioeconomic status (as measured by paternal occupation) and number of prior live births were higher among exposed pregnancies. In contrast, cigarette smoking, and alcohol consumption during the first trimester was less common among exposed pregnancies.

There was wide distribution of PCE exposure levels encompassing several orders of magnitude among the exposed pregnancies (Table 3). The median levels of cumulative exposure, maximum annual exposure, and average monthly exposure were 27, 16 and 0.55 grams, respectively. As previously described, the exposure measures were based on the mass of PCE delivered to a home in each calendar year. The annual mass of PCE entering a home was diluted in an estimated 90,000 gallons of water, the annual usage of average households in Massachusetts (Massachusetts Water Resources Authority 2003), and only a small portion of this water was directly consumed by the subjects. Using this annual estimate of household water use, we converted the PCE mass delivered to a home during pregnancy to average annual point concentrations and estimated that the PCE concentrations in the water entering the homes ranged from less than $1 \mu \mathrm{g} / \mathrm{L}$ to $5,197 \mu \mathrm{g} / \mathrm{L}$. These concentrations are consistent with actual water sampling data from the time period (Demond 1982).

When we compared the women's self-assessed exposure status to that derived from the EPANET assessment, we found that only $15 \%$ of women considered exposed by the EPANET assessment thought that their drinking water was contaminated, whereas $28 \%$ of these women thought that 
Table 2 Distribution of selected characteristics of exposed and unexposed pregnancies ${ }^{\mathrm{a}}$

\begin{tabular}{|c|c|c|c|c|c|c|c|c|}
\hline \multirow[t]{3}{*}{ Characteristic } & \multicolumn{4}{|c|}{ Exposed } & \multicolumn{4}{|c|}{ Unexposed } \\
\hline & \multicolumn{2}{|c|}{ Losses } & \multicolumn{2}{|c|}{ Live births } & \multicolumn{2}{|c|}{ Losses } & \multicolumn{2}{|c|}{ Live births } \\
\hline & $n$ & $\%$ & $n$ & $\%$ & $n$ & $\%$ & $n$ & $\%$ \\
\hline \multicolumn{9}{|l|}{ Year of pregnancy } \\
\hline Before 1968 & 0 & 0.0 & 0 & 0.0 & 55 & 12.3 & 347 & 11.0 \\
\hline 1968-1974 & 25 & 11.7 & 264 & 15.1 & 129 & 28.9 & 851 & 26.9 \\
\hline 1975-1980 & 93 & 43.7 & 749 & 43.0 & 137 & 30.7 & 1097 & 34.7 \\
\hline After 1980 & 95 & 44.6 & 730 & 41.9 & 125 & 28.0 & 870 & 27.5 \\
\hline \multicolumn{9}{|l|}{ Gestational duration } \\
\hline Up to 13 weeks & 170 & 79.8 & 0 & 0.0 & 350 & 78.5 & 0 & 0.0 \\
\hline 14-26 weeks & 24 & 11.3 & 9 & 0.5 & 79 & 17.7 & 12 & 0.4 \\
\hline$>26$ weeks & 19 & 8.9 & 1734 & 99.5 & 17 & 3.8 & 3153 & 99.6 \\
\hline $\begin{array}{l}\text { Maternal age } \\
(n, \text { mean })\end{array}$ & 211 & 29.0 & 1730 & 27.7 & 442 & 26.7 & 3147 & 26.0 \\
\hline $\begin{array}{l}\text { Paternal age } \\
(n, \text { mean })\end{array}$ & 202 & 31.2 & 1729 & 30.9 & 417 & 29.4 & 3109 & 29.0 \\
\hline \multicolumn{9}{|l|}{ Race } \\
\hline White & 197 & 92.5 & 1662 & 95.4 & 419 & 93.9 & 3021 & 95.5 \\
\hline Non-White & 14 & 6.6 & 77 & 4.4 & 22 & 4.9 & 132 & 4.2 \\
\hline Missing & 2 & 0.9 & 4 & 0.2 & 5 & 1.1 & 12 & 0.4 \\
\hline \multicolumn{9}{|l|}{ Educational level } \\
\hline$<$ High school & 7 & 3.3 & 27 & 1.5 & 6 & 1.3 & 70 & 2.2 \\
\hline High school graduate & 24 & 11.3 & 324 & 18.6 & 85 & 19.1 & 649 & 20.5 \\
\hline Some college & 71 & 33.3 & 602 & 34.5 & 164 & 36.8 & 1091 & 34.5 \\
\hline College graduate & 109 & 51.2 & 785 & 45.0 & 188 & 42.2 & 1348 & 42.6 \\
\hline Missing & 2 & 0.9 & 5 & 0.3 & 3 & 0.7 & 7 & 0.2 \\
\hline \multicolumn{9}{|l|}{ Paternal occupation } \\
\hline White collar & 114 & 53.5 & 888 & 50.9 & 207 & 46.4 & 1457 & 46.0 \\
\hline Blue collar & 63 & 29.6 & 566 & 32.5 & 141 & 31.6 & 1064 & 33.6 \\
\hline Other & 36 & 16.9 & 255 & 14.6 & 90 & 20.2 & 602 & 19.0 \\
\hline Missing & 0 & 0.0 & 34 & 2.0 & 8 & 1.8 & 42 & 1.3 \\
\hline \multicolumn{9}{|c|}{ Number of prior live births } \\
\hline 0 & 54 & 25.4 & 534 & 30.6 & 150 & 33.6 & 1354 & 42.8 \\
\hline 1 & 81 & 38.0 & 674 & 38.7 & 175 & 39.2 & 1012 & 32.0 \\
\hline $2+$ & 74 & 34.7 & 534 & 30.6 & 121 & 27.1 & 796 & 25.2 \\
\hline Missing & 4 & 1.9 & 1 & 0.1 & 0 & 0.0 & 3 & 0.1 \\
\hline \multicolumn{9}{|c|}{ Prior pregnancy losses before PCE exposure or index year ${ }^{b}$} \\
\hline Yes & 34 & 16.0 & 147 & 8.4 & 94 & 21.1 & 254 & 8.0 \\
\hline No & 177 & 83.1 & 1595 & 91.5 & 352 & 78.9 & 2908 & 91.9 \\
\hline Missing & 2 & 0.9 & 1 & 0.1 & 0 & 0.0 & 3 & 0.1 \\
\hline \multicolumn{9}{|c|}{ Cigarette smoking during first trimester } \\
\hline Some & 48 & 22.5 & 430 & 24.7 & 136 & 30.5 & 953 & 30.1 \\
\hline None & 164 & 77.0 & 1306 & 74.9 & 308 & 69.1 & 2183 & 69.0 \\
\hline Missing & 1 & 0.5 & 7 & 0.4 & 2 & 0.4 & 29 & 0.9 \\
\hline \multicolumn{9}{|c|}{ Alcohol consumption during first trimester } \\
\hline Some & 68 & 31.9 & 639 & 36.7 & 178 & 40.0 & 1182 & 37.3 \\
\hline None & 142 & 66.7 & 1093 & 62.7 & 265 & 59.4 & 1949 & 61.6 \\
\hline Missing & 3 & 1.4 & 11 & 0.6 & 3 & 0.7 & 34 & 1.1 \\
\hline
\end{tabular}


Table 2 (Continued)

\begin{tabular}{|c|c|c|c|c|c|c|c|c|}
\hline \multirow[t]{3}{*}{ Characteristic } & \multicolumn{4}{|c|}{ Exposed } & \multicolumn{4}{|c|}{ Unexposed } \\
\hline & \multicolumn{2}{|c|}{ Losses } & \multicolumn{2}{|c|}{ Live births } & \multicolumn{2}{|c|}{ Losses } & \multicolumn{2}{|c|}{ Live births } \\
\hline & $n$ & $\%$ & $n$ & $\%$ & $n$ & $\%$ & $\bar{n}$ & $\%$ \\
\hline \multicolumn{9}{|l|}{ Marijuana use during pregnancy } \\
\hline Yes & 8 & 3.8 & 57 & 3.3 & 14 & 3.1 & 128 & 4.0 \\
\hline No & 201 & 94.4 & 1665 & 95.5 & 429 & 96.2 & 2997 & 94.7 \\
\hline Missing & 4 & 1.9 & 21 & 1.2 & 3 & 0.7 & 40 & 1.3 \\
\hline Cervical Incompetence & 7 & 3.3 & 34 & 2.0 & 16 & 3.6 & 61 & 1.9 \\
\hline \multicolumn{9}{|l|}{ Occupational exposure to solvents } \\
\hline Yes, before or during pregnancy & 29 & 13.6 & 186 & 10.7 & 63 & 14.1 & 284 & 9.0 \\
\hline Yes, unknown when & 1 & 0.5 & 26 & 1.5 & 9 & 2.0 & 46 & 1.5 \\
\hline No & 178 & 83.6 & 1503 & 86.2 & 368 & 82.5 & 2784 & 88.0 \\
\hline Missing & 5 & 2.3 & 28 & 1.6 & 6 & 1.3 & 51 & 1.6 \\
\hline \multicolumn{9}{|l|}{ Use of solvent-based spot removers } \\
\hline Yes & 148 & 69.5 & 1127 & 64.7 & 313 & 70.2 & 2060 & 65.1 \\
\hline No & 60 & 8.2 & 581 & 33.3 & 127 & 28.5 & 1026 & 32.4 \\
\hline Missing & 5 & 2.3 & 35 & 2.0 & 6 & 1.3 & 79 & 2.5 \\
\hline \multicolumn{9}{|l|}{ Use of professional dry-cleaning } \\
\hline Yes & 187 & 87.8 & 1495 & 85.8 & 377 & 84.5 & 2703 & 85.4 \\
\hline No & 13 & 6.1 & 188 & 10.8 & 41 & 9.2 & 312 & 9.9 \\
\hline Missing & 13 & 6.1 & 60 & 3.4 & 28 & 6.3 & 150 & 4.7 \\
\hline \multicolumn{9}{|l|}{ Use of self-service dry-cleaning } \\
\hline Yes & 32 & 15.0 & 233 & 13.4 & 78 & 17.5 & 526 & 16.6 \\
\hline No & 174 & 81.7 & 1456 & 83.5 & 361 & 80.9 & 2549 & 80.5 \\
\hline Missing & 7 & 3.3 & 54 & 3.1 & 7 & 1.6 & 90 & 2.8 \\
\hline Surface water supply during LMP year & 71 & 33.3 & 601 & 34.5 & 22 & 4.9 & 166 & 5.2 \\
\hline
\end{tabular}

${ }^{a}$ Exposure status during LMP year of each pregnancy

${ }^{b}$ Prior losses before exposure for PCE exposed pregnancies or a comparable index year for unexposed pregnancies

their water was not contaminated and 57\% were unsure. Similarly, we found that $37 \%$ of women considered unexposed by the EPANET assessment thought that their drinking water was not contaminated while $9 \%$ thought that their drinking water was contaminated and 53\% were unsure.

The crude and multivariate adjusted odds ratios for pregnancy loss were quite similar across exposure categories (Table 4). For example, compared to women who were unexposed during the LMP year, the multivariate GEE odds ratios were $1.1,0.7,0.8$ and 0.7 for women whose average monthly PCE exposure during the LMP year ranged from the lowest to highest exposure quartile. Similar results were seen when cumulative and peak PCE exposures were examined. In addition, the multivariate GEE odds ratio for pregnancy loss was not elevated (OR: 0.8, 95\% CI: 0.6-1.1) among women whose average monthly exposure during the LMP year was greater than 1.136 grams, a cut point which corresponds to an average drinking water concentration of
$40 \mu \mathrm{g} / \mathrm{L}$. The results were unchanged when the pregnancies were stratified according to year of pregnancy.

The exposed and unexposed losses had a similar distribution of gestational duration (Table 2). When the losses were stratified by trimester, we did not observe any increases in the risk of either early or late pregnancy losses according to any of the exposure measures (Table 5).

There was also no evidence of effect measure modification by maternal age, history of prior losses, medical conditions, alcoholic beverage and cigarette smoking during the first trimester, and residence in the town of Falmouth (data not shown).

\section{Discussion}

The results of this study suggest that prenatal PCE exposure, at the levels experienced by this population, does not increase the risk of clinically recognized pregnancy loss. 
Table 3 Distributions of cumulative exposure ( $\mathrm{g}$ ) up to LMP month and year, maximum annual exposure ( $\mathrm{g}$ ) before, LMP year, and average monthly exposure (g) during LMP year among PCE exposed pregnancies

\begin{tabular}{llll}
\hline & $\begin{array}{l}\text { Cumulative } \\
\text { exposure } \\
\text { up to LMP } \\
\text { month and year }\end{array}$ & $\begin{array}{l}\text { Maximum } \\
\text { annual } \\
\text { exposure } \\
\text { before } \\
\text { LMP year }\end{array}$ & $\begin{array}{l}\text { Average } \\
\text { monthly } \\
\text { during } \\
\text { LMP year }\end{array}$ \\
\hline$n$ & $2,395^{\mathrm{a}}$ & $2,047^{\mathrm{a}}$ & $1,956^{\mathrm{a}}$ \\
Minimum & $2.8 \mathrm{E}-04$ & $1.2 \mathrm{E}-03$ & $7.5 \mathrm{E}-05$ \\
10th percentile & 1 & $10.0 \mathrm{E}-01$ & $2.3 \mathrm{E}-02$ \\
25th percentile & 6 & 4 & $1.2 \mathrm{E}-01$ \\
Median & 27 & 16 & $5.5 \mathrm{E}-01$ \\
75 th percentile & 113 & 55 & 2 \\
90th percentile & 334 & 145 & 6 \\
Maximum & 4,019 & 1,698 & 132 \\
\hline
\end{tabular}

a 439 subjects were exposed only before the LMP year, 348 subjects were exposed only during the LMP year, and 1,608 subjects were exposed both before and during the LMP year. Thus, 2,395 subjects $(439+1608+439+348)$ contributed to the measure of cumulative exposure up to the LMP month and year, 2,047 subjects $(1608+439)$ contributed to the maximum exposure before the LMP year, and 1,956 subjects $(1608+348)$ contributed to the average monthly exposure during the LMP year

Table 4 Frequencies, odds ratios and 95\% confidence intervals for pregnancy loss according to PCE exposure

\begin{tabular}{|c|c|c|c|c|}
\hline & $\begin{array}{l}\text { Number of } \\
\text { losses }\end{array}$ & $\begin{array}{l}\text { Number of } \\
\text { live births }\end{array}$ & $\begin{array}{l}\text { Crude } \\
\text { odds ratio } \\
(95 \% \mathrm{CI})\end{array}$ & $\begin{array}{l}\text { Multivariate } \\
\text { GEE odds ratio } \\
(95 \% \mathrm{CI})\end{array}$ \\
\hline \multicolumn{5}{|c|}{ Cumulative PCE exposure up to LMP (g) } \\
\hline$\geq 75$ th percentile & 70 & 529 & $1.0(0.8-1.3)$ & $0.9(0.7-1.3)$ \\
\hline 50 th $-<75$ th percentile & 69 & 530 & $1.0(0.7-1.3)$ & $0.8(0.6-1.2)$ \\
\hline 25 th $-<50$ th percentile & 68 & 531 & $1.0(0.7-1.3)$ & $0.9(0.6-1.3)$ \\
\hline$>0-<25$ th percentile & 76 & 522 & $1.1(0.8-1.4)$ & $1.1(0.8-1.5)$ \\
\hline 0 (Referent) & 376 & 2796 & $1.0(-)$ & $1.0(-)$ \\
\hline \multicolumn{5}{|c|}{ Maximum Annual PCE Before LMP Year (g) } \\
\hline$\geq 75$ th percentile & 63 & 449 & $1.1(0.8-1.4)$ & $1.1(0.8-1.5)$ \\
\hline 50 th $-<75$ th percentile & 67 & 517 & $1.2(0.9-1.5)$ & $1.1(0.8-1.7)$ \\
\hline 25 th $-<50$ th percentile & 53 & 507 & $0.9(0.7-1.2)$ & $0.8(0.5-1.1)$ \\
\hline$>0-<25$ th percentile & 74 & 511 & $1.3(1.0-1.7)$ & $1.4(1.0-1.9)$ \\
\hline 0 (Referent) & 402 & 3118 & $1.0(-)$ & $1.0(-)$ \\
\hline \multicolumn{5}{|c|}{ Average Monthly PCE Exposure During LMP Year (g) } \\
\hline$\geq 75$ th percentile & 46 & 443 & $0.7(0.5-1.0)$ & $0.7(0.5-1.0)$ \\
\hline 50 th $-<75$ th percentile & 48 & 441 & $0.8(0.6-1.1)$ & $0.8(0.6-1.2)$ \\
\hline 25 th $-<50$ th percentile & 53 & 436 & $0.9(0.6-1.2)$ & $0.7(0.5-1.1)$ \\
\hline$>0-<25$ th percentile & 66 & 423 & $1.1(0.8-1.5)$ & $1.1(0.8-1.6)$ \\
\hline 0 (Referent) & 446 & 3165 & $1.0(-)$ & $1.0(-)$ \\
\hline
\end{tabular}

${ }^{a}$ Controlled for maternal age, paternal age, maternal history of gynecologic infections, number of prior live births, and year of pregnancy

As compared to unexposed pregnancies, the adjusted odds ratios for pregnancy loss were either at or below the null among women whose PCE exposure levels ranged from the lowest to highest quartile. Furthermore, no elevation in risk was observed among women whose average monthly exposure during the LMP year was greater than 1.136 grams, 
Table 5 Frequencies, odds ratios and 95\% confidence intervals for first and second/third trimester pregnancy loss according to PCE exposure

Number of
losses

losses

Number of
live births

live births
Crude

odds ratio

(95\% CI)
Multivariate $^{\mathrm{a}}$

GEE odds ratio

$(95 \% \mathrm{CI})$

First trimester losses

Cumulative PCE exposure up to LMP (g)

$\begin{array}{lll}\geq 75 \text { th percentile } & 56 & 529 \\ 50 \text { th }-<75 \text { th percentile } & 51 & 530 \\ 25 \text { th }-<50 \text { th percentile } & 48 & 531 \\ >0-<25 \text { th percentile } & 66 & 522 \\ 0 \text { (Referent) } & 299 & 2796\end{array}$

Maximum annual PCE before LMP year (g)

$\begin{array}{lll}\geq 75 \text { th percentile } & 50 & 449 \\ 50 \text { th }-<75 \text { th percentile } & 54 & 450 \\ 25 \text { th }-<50 \text { th percentile } & 34 & 454 \\ >0-<25 \text { th percentile } & 63 & 437 \\ 0 \text { (Referent) } & 319 & 3118\end{array}$

Average monthly PCE exposure during LMP year (g)

$\begin{array}{lll}\geq 75 \text { th percentile } & 38 & 443 \\ 50 \text { th }-<75 \text { th percentile } & 34 & 441 \\ 25 \text { th }-<50 \text { th percentile } & 41 & 436 \\ >0-<25 \text { th percentile } & 57 & 423 \\ 0 \text { (Referent) } & 350 & 3165\end{array}$

Second/third trimester losses

Cumulative PCE exposure up to LMP (g)

$\begin{array}{lll}\geq 75 \text { th percentile } & 14 & 529 \\ 50 \text { th }-<75 \text { th percentile } & 18 & 530 \\ 25 \text { th }-<50 \text { th percentile } & 20 & 531 \\ >0-<25 \text { th percentile } & 10 & 522 \\ 0 \text { (Referent) } & 77 & 2796\end{array}$

$1.0(0.5-1.7)$

$0.8(0.4-1.7)$

$1.2(0.7-2.1)$

$0.8(0.4-1.7)$

$1.4(0.8-2.3)$

$1.3(0.7-2.2)$

$0.7(0.4-1.4)$

$0.7(0.4-1.5)$

0 (Referent)

$1.0(-)$

$1.0($ ( )

Maximum annual PCE before LMP year (g)

$\begin{array}{lll}\geq 75 \text { th percentile } & 13 & 449 \\ 50 \text { th }-<75 \text { th percentile } & 13 & 450 \\ 25 \text { th }-<50 \text { th percentile } & 19 & 454 \\ >0-<25 \text { th percentile } & 11 & 437 \\ 0 \text { (Referent) } & 83 & 3118\end{array}$

Average monthly PCE exposure during LMP year (g)

$\begin{array}{lll}\geq 75 \text { th percentile } & 8 & 443 \\ 50 \text { th }-<75 \text { th percentile } & 14 & 441 \\ 25 \text { th }-<50 \text { th percentile } & 12 & 436 \\ >0-<25 \text { th percentile } & 9 & 423 \\ 0 \text { (Referent) } & 96 & 3165\end{array}$

$\begin{array}{ll}1.1(0.6-2.0) & 1.0(0.5-2.1) \\ 1.1(0.6-2.0) & 0.9(0.4-1.9) \\ 1.6(0.9-2.6) & 1.3(0.7-2.3) \\ 0.9(0.5-1.8) & 1.0(0.5-1.9) \\ 1.0(-) & 1.0(-) \\ 0.6(0.3-1.2) & 0.6(0.2-1.3) \\ 1.0(0.6-1.8) & 1.0(0.5-1.9) \\ 0.9(0.5-1.7) & 0.6(0.3-1.5) \\ 0.7(0.4-1.4) & 0.7(0.3-1.4) \\ 1.0(-) & 1.0(-)\end{array}$

${ }^{a}$ Controlled for maternal age, paternal age, maternal history of gynecologic infections, number of prior live births, and year of pregnancy

a cutpoint which corresponds to an average drinking water concentration of $40 \mu \mathrm{g} / \mathrm{L}$, the Suggested Action Guide when the PCE contamination was discovered.

A causal interpretation of the results of these findings is tempered by likely exposure misclassification. Because indi- vidual level exposure measurements were not available for the study period, we estimated historical PCE exposures using a leaching and transport model developed by Webler and Brown (1993) that predicted the mass of PCE delivered to each residence. The model was applied to water distribution 
system conditions in 1980 assumed to be representative of the entire study period. Further misclassification arose from our inability to incorporate water consumption and bathing habits into the analysis because mothers had poor recall of this information.

On the other hand, results from two validation studies indicate good correlation between PCE concentrations in historical water samples and exposure estimates based on the original Webler-Brown flow algorithm (Spearman correlation coefficient $=0.48, p<0.0001)$ (Spence et al. 2008), as well as exposure estimates based on the EPANET water distribution system modeling software (Spearman correlation coefficient $=0.65, p<0.001)$ (Gallagher et al. unpublished manuscript). While these validation study results suggest that the magnitude of exposure misclassification is relatively small, particularly given the quartile exposure categories used in the current analysis, it likely hampered our ability to detect a modest increase in the risk of pregnancy loss.

Another limitation arose from our use of self-reported pregnancy losses. While some under-reporting of clinically recognized losses was likely (11.8\% of reported pregnancies ended in a loss and $24.2 \%$ of women had a history of a loss), results of our outcome validation study, albeit small in size, showed good reporting of pregnancy outcomes and related behaviors. Furthermore, the proportion of reported losses was stable over time and the breakdown of losses by trimester was as expected. Lastly, our analyses of index births found good agreement between the number of pregnancy terminations (induced and spontaneous) reported by the women and on the birth certificate.

Another limitation of the study arose from using birth certificates to identify women for the parent study. While parity was controlled in the present analysis, these results may not be generalizable to women who never achieve a live birth, an estimated $12 \%$ of women in the United States (Chandra et al. 2005).

The present study has numerous strengths, including a relatively large number of pregnancy losses, a wide range and irregular pattern of exposure, and information on many confounding variables. In addition, confounding by unmeasured drinking water contaminants was unlikely. Trihalomethane levels in this region were low because only one surface water source was treated. Furthermore, the results were unchanged when we controlled for residence in Falmouth, the only study town with a chlorinated surface water supply. While non-participating mothers were younger and less educated than participating mothers, these differences were present for both exposed and unexposed nonparticipants, and so it is unlikely that selection bias influenced the current results. Recall bias was also unlikely because the PCE exposure assessments were conducted blindly with respect to the pregnancy outcome information.
Furthermore, there was poor agreement between a woman's self-assessed exposure and the exposure status derived independently for the study. In fact, most women were unsure if their own drinking water had been contaminated with PCE.

Several animal experiments suggest that PCE and TCE cause species- and dose-specific increases in embryotoxicity. Increased rates of resorbed implants and fetuses have been observed in many studies of pregnant rats exposed to low, moderate and high doses of these chemicals (e.g., 100 to 1000 ppm for inhalation doses) (Healy et al. 1982; Smith et al. 1989; Schwetz et al. 1975; Narotsky and Kavlock 1995; Tinston 1995). The proportion of dead embryos also increased in a dose-dependent fashion among fertilized Leghorn chick eggs whose air space was injected with 5-100 $\mu \mathrm{mol}$ PCE and TCE (Elovaara et al. 1979). Lastly, increased resorptions have been seen among rabbits with inhalation exposures of 500 ppm PCE and TCE. In contrast, no evidence of embryotoxicity has been observed among mice exposed to low and moderate doses (i.e., 100-500 ppm) (Beliles et al. 1980; Hardin et al. 1981; Schwetz et al. 1975).

Many epidemiological studies also have found a positive association between maternal occupational exposure to solvent mixtures and the risk of pregnancy loss (e.g., Khattak et al. 1999); however, results are often difficult to interpret because many types of solvents and jobs were included in the exposed group. Nevertheless, numerous studies with more specific exposure definitions, such as drycleaning work or PCE exposure, have measured an increased relative risk of pregnancy loss (e.g., Bosco et al. 1987; Kyyronen et al. 1989; Kolstad et al. 1990; Olsen et al. 1990; Lindbohm et al. 1990; Windham et al. 1991; Doyle et al. 1997). The reported relative risks range from about 1.4 to 4.0. In contrast, a few occupational studies did not find any increases in the risk of pregnancy loss among laundry and dry-cleaning workers (e.g, Ahlborg 1990; McDonald et al. 1987), but the broad exposure categories likely biased these results toward the null.

Studies by Windham et al. (1991) and Doyle et al. (1997) were among the largest of the occupational studies with positive associations, with 628 and 422 pregnancy losses, respectively. The case-control study by Windham et al. found a 3.4-fold increased risk of spontaneous abortion (95\% CI: 1.0-12.0) among pregnant women with occupational exposure to PCE and/or TCE, while the retrospective cohort study by Doyle et al. found a 1.6-fold increased risk $(95 \%$ CI: 1.1-2.7) among women employed as dry-cleaning operators with a high likelihood of PCE exposure.

A likely reason for the discrepancy between our null results and the positive associations seen in these occupational studies is the difference in exposure levels. Allowable occupational exposure levels for PCE are relatively high (ATSDR 
1997), especially in comparison to the environmental exposures experienced by most of our study population. In addition, occupational studies comparing working and nonworking women, such as those by Bosco et al. (1987) and Doyle et al. (1997), may have an upward bias because women whose pregnancy history is comprised only of adverse outcomes such as pregnancy losses are more likely to remain in the work force, while those who have had live born children are more likely to drop out (Joffe 1985). The study by Windham et al. (1991) specifically limited the analyses to working women to avoid this problem.

Furthermore, the increased risks among women with occupational exposures may not be generalizable to women in the general population because solvent-exposed women come mainly from low socioeconomic strata. In addition, women who either cannot find work or do not have a monetary incentive to work are not represented in the occupational studies.

Prior population-based studies of solvent contaminated drinking water are more analogous to the current investigation. Only three prior drinking water studies have examined PCE and TCE contamination in relation to pregnancy loss, and two of the three studies have null results. A crosssectional study from New Jersey found no increase in the risk of fetal death in relation to PCE or TCE exposure using town-level exposure data provided by the water companies and vital records data on fetal deaths occurring at $>20$ weeks' gestation (Bove et al. 1995, 2002).

Another cross-sectional study in Woburn, Massachusetts, found no elevation in the risk of spontaneous abortion in relation to the fraction of residential water obtained from two contaminated wells during the year the pregnancy ended (Lagakos et al. 1986). The two wells, known as Wells G and $\mathrm{H}$, were contaminated with TCE $(267 \mu \mathrm{g} / \mathrm{L}), \mathrm{PCE}(21 \mu \mathrm{g} / \mathrm{L})$, and several other chemicals. Woburn Study investigators obtained data on spontaneous abortions from subject interviews, and estimated prenatal exposure to the contaminated wells using a water distribution model. In contrast, a followup study in Woburn found a 1.8-fold increased risk of fetal death among women with any exposure during pregnancy (95\% CI: 0.4-6.6), and a 2.6-fold increased risk (95\% CI: 0.7-8.9) among women with high exposure during pregnancy (Massachusetts Department of Public Health 1996; Bove et al. 2002). In the follow-up study, reports of fetal deaths were obtained from the Massachusetts Registry of Vital Records, and included only deaths at $\geq 20$ weeks' gestation or in fetuses weighing $\geq 350$ grams. In addition, a more sensitive model of the water distribution system estimated prenatal exposures.

Taken together, the results of the present and prior studies do not provide strong evidence of an increased risk of clinically recognized pregnancy loss in relation to PCE exposure from drinking water. However, weaknesses in these studies, including the present one, may have made it difficult to observe a modestly increased risk. Furthermore, our results are not generalizable to women with unrecognized pregnancy loss or to women who have never achieved a live birth. Because PCE remains a commercially ubiquitous solvent and common contaminant of ground and drinking water supplies (Moran et al. 2007; ATSDR 1997), it is important to understand its effect on women and their pregnancies.

Acknowledgements This work was supported by grant number 5 P42 ES007381 from the National Institute of Environmental Health (NIEHS), NIH. Its contents are solely the responsibility of the authors and do not necessarily represent the official views of NIEHS, NIH.

Open Access This article is distributed under the terms of the Creative Commons Attribution Noncommercial License which permits any noncommercial use, distribution, and reproduction in any medium, provided the original author(s) and source are credited.

\section{References}

Agency for Toxic Substances Disease Registry (ATSDR) (1997) Toxicological profile for 1,1,2,2-tetrachloroethylene

Ahlborg G (1990) Pregnancy outcome among women working in laundries and dry-cleaning shops using tetrachloroethylene. Am J Indust Med 17:567-575

Aral MM, Maslia ML, Ulirsch GV, Reyes JJ (1996) Estimating exposure to volatile organic compounds from municipal water-supply systems: use of a better computational model. Arch Environ Health 51(4):300-309

Aschengrau A, Rogers S, Ozonoff D (2003) Perchloroethylenecontaminated drinking water and the risk of breast cancer: additional results from Cape Cod, Massachusetts. Environ Health Perspect 111:167-173

Aschengrau A, Weinberg J, Rogers S, Gallagher L, Winter M, Vieira V, Webster T, Ozonoff D (2008) Prenatal exposure to tetrachloroethylene-contaminated drinking water and the risk of adverse birth outcomes. Environ Health Perspect 116:814-820

Beliles RP, Brusick DJ, Mecler FJ (1980) Teratogenic-mutagenic risk of workplace contaminants: trichloroethylene, perchloroethylene, and carbon disulfide. NIOSH Contract Report No. 210-77-0047. NTIS Publ. No. PB-82-185-075. National Technical Information Service, Springfield, VA

Bosco MG, Figa-Talamanca I, Salerno S (1987) Health and reproductive status of female workers in dry-cleaning shops. Int Arch Occup Environ Health 59:295-301

Bove FJ, Fulcomer MC, Klotz JB, Esmart J, Dufficy EM, Savrin JE (1995) Public drinking water contamination and birth outcomes. Am J Epidemiol 141:850-862

Bove F, Shim Y, Zeitz P (2002) Drinking water contaminants and adverse pregnancy outcomes: a review. Environ Health Perspect 110:61-74

Bross G, DiFranceisco DM (1983) The effects of low dosages of trichloroethylene on chick development. Toxicology 28:283-294

Chandra A, Martinez GM, Mosher WD, Abma J, Jones J (2005) Fertility, family planning, and reproductive health of US women: Data from the 2002 National Survey of Family Growth. National Center for Health Statistics. Vital Health Stat 23(25)

Demond AH (1982) A source of tetrachloroethylene in the drinking water of New England: An evaluation of toxicity of tetrachloroethylene and the prediction of its leaching rates from vinyllined asbestos-cement pipe [MS Thesis]. Massachusetts Institute of Technology, Cambridge, MA 
Doyle P, Roman E, Beral V, Brookes M (1997) Spontaneous abortion in dry cleaning workers potentially exposed to perchloroethylene. Occup Environ Med 54:848-853

Elovaara E, Hemminki K, Vainio H (1979) Effects of methylene chloride, trichloroethane, trichloroethylene, tetrachloroethylene, and toluene on the development of chick embryos. Toxicology 12:111-119

Gallagher L, Ozonoff D, Webster TF, Vieira V, Aschengrau A (Unpublished manuscript) Exposure assessment of PCE-contaminated drinking water using a water distribution system model on Cape Cod, Massachusetts

Gallagher MD, Nuckols JR, Stallones L, Savitz DA (1998) Exposure to trihalomethanes and adverse pregnancy outcomes. Epidemiol 9:484-489

Gilboa SM, Mendola P, Olshan AF, Harness C, Loomis D, Langlois PH, Savitz DA, Herring AH (2006) Comparison of residential geocoding methods in population-based study of air quality and birth defects. Environ Res 101:256-262

Hardin B, Bond GP, Sikov MR, Andrew FD, Beliles RP, Niemeier RW (1981) Testing of selected workplace chemicals for teratogenic potential. Scand J Work Environ Health 7(4):66-75

Hastie TJ, Tibshirani RJ (1990) Generalized additive models. Chapman and Hall, London, pp 29-31

Healy TEJ, Poole TR, Hopper A (1982) Rat fetal development and maternal exposure to trichloroethylene $100 \mathrm{ppm}$. Br J Anaesth 54:337-341

International Agency for Research on Cancer (IARC) (1995) IARC monographs on the evaluation of carcinogenic risks to humans. Dry-cleaning, some chlorinated solvents and other industrial chemicals, vol. 63. Lyons, France

Janulewicz P, White R, Winter M, Weinberg J, Gallagher L, Vieira V, Webster T, Aschengrau A (2008) Learning disabilities following prenatal and early postnatal exposure to tetrachloroethylene(PCE)-contaminated drinking water. Neurotox Teratol 30:175-185

Joffe M (1985) Biases in research on reproduction and women's work. Int J Epidemiol 14:118-123

Khattak S, Moghtader GK, McMartin K, Barrera M, Kennedy D, Koren G (1999) Pregnancy outcome following gestational exposure to organic solvents: a prospective controlled study. J Am Med Assoc 281:1106-1109

Kolstad HA, Brandt LPA, Rasmussen KC (1990) Klorerede oplosningsmidler og fosterskader. Ogeskr Laeger 152:2481-2482

Kyyronen P, Taskinen H, Lindbohm ML, Hemminki K, Heinonen OP (1989) Spontaneous abortions and congenital malformations among women exposed to tetrachloroethylene in dry cleaning. J Epidemiol Comm Health 43:346-351

Lagakos SW, Wessen BJ, Zelen M (1986) An analysis of contaminated well water and health effects in Woburn, Massachusetts. J Am Stat Assoc 81:583-596

Liang KY, Zeger SL (1986) Longitudinal data analysis using generalized linear models. Biometrika 73:13-22

Lindbohm MJ, Taskinen H, Sallmen M, Hemminki K (1990) Spontaneous abortion among women exposed to organic solvents. Am J Ind Med 17:449-463

Maslia ML, Sautner JB, Aral MM, Reyes JJ, Abraham JE, Williams RC (2000) Using water-distribution system modeling to assist epidemiologic investigations. J Water Res Plan Manag 126(4):180198

Massachusetts Department of Public Health (1996) The woburn environment and birth study synopsis. Massachusetts Department of Public Health, Boston
Massachusetts Water Resources Authority (2003) MWRA annual report on your drinking water. Available at: http://www.mwra.state. ma.us/annual/waterreport/2005results/2005metro.pdf. Accessed 28 May 2008

McDonald AD, McDonald JC, Armstrong B, Cherry N, Delorme C (1987) Occupation and pregnancy outcome. Br J Ind Med 44:521526

McElroy JA, Remington PL, Trentham-Dietz A, Robert SA, Newcomb PA (2003) Geocoding addresses from a large population-based study: lessons learned. Epidemiology 14:399-407

Moran MJ, Zogorski JS, Squillance PJ (2007) Chlorinated solvents in groundwater of the United States. Environ Sci Tech 41:74-81

Narotsky MG, Kavlock RJ (1995) A multidisciplinary approach to toxicological screening: II developmental toxicity. J Toxicol Environ Health 45:145-171

Nelson BK, Taylor BJ, Setzer JV, Hornung RW (1980) Behavioral toxicology of perchloroethylene in rats. J Environ Path Toxicol 3:233250

Olsen J, Hemminki K, Ahlborg G, Bjerkedal T, Kyyronen P, Taskinen $\mathrm{H}$ et al (1990) Low birthweight, congenital malformations, and spontaneous abortions among dry-cleaning workers in Scandinavia. Scand J Work Environ Health 16:163-168

Reif JS, Burch JB, Nuckols JR, Metzger L, Anger WK (2003) Neurobehavioral effects of exposure to trichloroethylene through a municipal water supply. Environ Res 9:248-258

Rossman LA (1994) EPANET users manual. US Environmental Protection Agency, Risk Reduction Engineering Laboratory, Cincinnati

Schwetz BA, Leong BKJ, Gehring PJ (1975) The effect of maternally inhaled trichloroethylene, perchloroethylene, methyl chloroform, and methylene chloride on embryonal and fetal development in mice and rats. Toxicol Appl Pharmacol 32:84-96

Smith MK, Randall JL, Read EJ, Stober JA (1989) Teratogenic activity of trichloroacetic acid in the rat. Teratology 40:445-451

Spence LA, Aschengrau A, Gallagher L, Webster T, Heeren T, Ozonoff D (2008) Evaluation of a model for estimating tetrachloroethylene exposure from vinyl-lined asbestos-cement pipes. Envinron Health 7:24

Swartz CH, Rudel RA, Kachajian JR, Brody JG (2003) Historical reconstruction of wastewater and land use impacts to ground water used for public drinking water: exposure assessment using chemical data and GIS. J Exp Anal Environ Epidemiol 13:403-416

Tinston DJ (1995) Perchloroethylene: Multigenerational inhalation study in the rat. Report No. CTL/P/4097. Sponsored by the Halogenated Solvents Industry Alliance, HSIA/90/0002

US Department of Health Human Services, Public Health Service, National Toxicology Program (2005) Report of carcinogens, 11th edn

Webler T, Brown HS (1993) Exposure to tetrachloroethylene via contaminated drinking water pipes in Massachusetts: a predictive model. Arch Environ Health 48(5):293-297

Whelan EA, Lawson CC, Grajewski B, Hibert EN, Spiegelman D, Rich-Edwards JW (2007) Work schedule during pregnancy and spontaneous abortion. Epidemiology 18(3):350-355

Windham GC, Shusterman D, Swan SH, Fenster L, Eskenazi B (1991) Exposure to organic solvents and adverse pregnancy outcome. Am J Ind Med 20:241-259

Zeger SL, Liang KY (1986) Longitudinal data analysis for discrete and continuous outcomes. Biometrics 42:121-130 